\title{
General and Electrophysiological Toxic Effects of Manganese in Rats following Subacute Administration in Dissolved and Nanoparticle Form
}

\author{
Edina Horváth,, ${ }^{1}$ Zsuzsanna Máté, ${ }^{1}$ Szabolcs Takács, ${ }^{1}$ Péter Pusztai, ${ }^{2}$ András Sápi, ${ }^{2}$ \\ Zoltán Kónya, ${ }^{2}$ László Nagymajtényi, ${ }^{1}$ and András Papp ${ }^{1}$ \\ ${ }^{1}$ Department of Public Health, University of Szeged Faculty of Medicine, Dóm tér 10., 6720 Szeged, Hungary \\ ${ }^{2}$ Department of Applied Chemistry, University of Szeged Faculty of Science and Informatics, Rerrich Béla tér 1., \\ 6720 Szeged, Hungary
}

Correspondence should be addressed to Edina Horváth, korosine.edina@med.u-szeged.hu

Received 14 October 2011; Accepted 5 December 2011

Academic Editors: N. Futrakul and J. L. Labandeira-García

Copyright ( 2012 Edina Horváth et al. This is an open access article distributed under the Creative Commons Attribution License, which permits unrestricted use, distribution, and reproduction in any medium, provided the original work is properly cited.

\begin{abstract}
In an attempt to model occupational and environmental Mn exposures and their possible interaction, young male Wistar rats were exposed to $\mathrm{Mn}$ by oral administration in dissolved form $\left(\mathrm{MnCl}_{2} \cdot 4 \mathrm{H}_{2} \mathrm{O}, 14.84\right.$ and $59.36 \mathrm{mg} / \mathrm{kg}$ b.w. $)$ and by intratracheal application of $\mathrm{MnO}_{2}$ nanoparticles ( $2.63 \mathrm{mg} / \mathrm{kg}$ b.w.). After 3 and 6 weeks oral, or 3 weeks oral plus 3 weeks intratracheal, exposure, general toxicological, and electrophysiological tests were done. Body weight gain was significantly reduced after 6 and 3 plus 3 weeks exposure, but the effect of the latter on the pace of weight gain was stronger. Organ weights signalized systemic stress and effect on lungs. Changes in evoked electrophysiological responses (cortical sensory evoked potential and nerve action potential) indicated that the 3 plus 3 weeks combined exposure caused equal or higher changes in the latency of these responses than 6 weeks of exposure, although the calculated summed Mn dose in the former case was lower. The results showed the importance of the physicochemical form of $\mathrm{Mn}$ in determining the toxic outcome, and suggested that neurofunctional markers of Mn action may indicate the human health effect better than conventional blood Mn measurement.
\end{abstract}

\section{Introduction}

It has been recognized in the last ca. 20 years that people's exposure to nanoparticles (NPs)s-let them be pollutants or components in nanotechnological products-has major influence on health. NPs are, by definition, particles which measure less than $100 \mathrm{~nm}$ in all three directions. In this size range, the surface-to-mass ratio becomes extremely high, meaning that this particle fraction (also called ultrafine dust) represents only a small mass fraction in any (environmental or occupational) dust sample but a high number of particles with a very high and reactive overall surface [1]. The small size also means that, once absorbed, NPs have extreme mobility within the (animal or human) organism and can reach all parts of it by crossing conventional barriers such as the alveolar or capillary wall. This, and the inflammogenic nature of NPs, is strongly influenced by their surface characteristics [2].

Concerning manganese $(\mathrm{Mn})$, both fine and ultrafine particles containing this metal are likely generated in various phases of production and processing of $\mathrm{Mn}$, from ore mining through steel casting and welding to the production of dry batteries; so that particle inhalation is a major way of-primarily occupational-exposure to this metal. The human nervous system effects of chronic Mn exposure are manifested by a state called manganism, a set of symptoms that is similar to Parkinson' disease and appears frequently in welders inhaling metal fumes [3]. Such exposure is typically job-related (but see [4]) while the general public might experience particulate $\mathrm{Mn}$ inhalation due to the use of methylcyclopentadienyl manganese tricarbonyl (MMT) as an antiknock petrol additive in some countries [5]. 
Manganese-induced Parkinsonism was, however, also observed in patients undergoing maintenance hemodialysis [6] or in inadvertent overdosing due to long-term ingestion of a health supplement containing high levels of $\mathrm{Mn}$, which indicates that other physicochemical forms of Mn and other routes of exposure are also relevant to the health of the CNS. For geological reasons (e.g., in Greece [7]) or due to man-made pollution (such as improper disposal of used dry cells in Japan [8]) abnormally high Mn levels in the drinking water were observed, together with CNS symptoms of the affected population. In regions of the USA with high-Mn drinking water, loss of visual and verbal memory, typical for Mn-induced brain damage, was described [9]. The neurotoxic spectrum of $\mathrm{Mn}$ is variable: epileptic activity was observed in children following inhalational Mn exposure [4] or prolonged total parenteral nutrition [10], and alterations in EEG and evoked potential were seen in shipyard workers [11].

Based on the above literature data, indicating the relevance of both inhalational and oral exposure by $\mathrm{Mn}$ to nervous system effects, the present study was aimed at investigating the adverse neurofunctional effects in rats, caused by Mn in different physicochemical forms (by inhaled Mn NPs and by dissolved Mn taken up orally). Our goal was to create an experimental model reproducing complex human Mn exposure-including occupational and nutritional sources-more adequately, and to detect the effects by electrophysiological methods, the suitability of which was proven in previous works $[12,13]$.

\section{Materials and Methods}

2.1. Animals and Treatment. Young adult male Wistar rats (7 weeks old, body weight $200 \pm 20 \mathrm{~g}$ ) were obtained from the breeding centre of the university and were housed in a GLPrated animal house $\left(22 \pm 1^{\circ} \mathrm{C}, 30-60 \%\right.$ relative humidity, $12 \mathrm{~h}$ light/dark cycle with light on at 06:00), with free access to tap water and standard pellet (at start, there were 12 groups of 12 rats each; this number allowed for eventual losses during treatment, finally 8 rats per group were chosen randomly for evaluation).

Treatments, representing oral and inhalational exposure, were performed once daily, 5 times a week, and lasted altogether 3 or 6 weeks (see Table 1 for group codes, doses, and treatment times). The oral doses were based on an earlier work of us [14] where 14.84 and $59.36 \mathrm{mg} / \mathrm{kg}$ b.w. of $\mathrm{MnCl}_{2}$ were given by gavage for several weeks. The intratracheal dose of $2.63 \mathrm{mg} / \mathrm{kg}$ b.w. of $\mathrm{MnO}_{2}$ NPs was likewise tested in a previous experiment [12].

For oral application, manganese chloride $\left(\mathrm{MnCl}_{2} 4 \mathrm{H}_{2} \mathrm{O}\right.$; Reanal, Hungary; purity 99.5\%) was dissolved in distilled water to $1 \mathrm{~mL} / \mathrm{kg}$ b.w. administration volume and was given to the rats by gavage. The NPs used for intratracheal application consisted of $\mathrm{MnO}_{2}$, had $23.2 \pm 3.3 \mathrm{~nm}$ diameter, and were synthesized at the Department of Applied Chemistry, University of Szeged by a technique combining sonication and hydrothermal treatment (see [13] for details). The NPs were suspended in $1 \%$ hydroxyethyl cellulose (HEC)
TABLE 1: Treatment scheme with group codes, doses and treatment times.

\begin{tabular}{ll}
\hline Group code & Treatment and dose \\
\hline C3 & 3 weeks, untreated \\
VC3 & 3 weeks, distilled water, orally \\
MnL3 & 3 weeks $14.84 \mathrm{mg} / \mathrm{kg}$ b.w. $\mathrm{MnCl}_{2}$, orally \\
MnH3 & 3 weeks $59.36 \mathrm{mg} / \mathrm{kg}$ b.w. $\mathrm{MnCl}_{2}$, orally \\
C33 & 6 weeks, untreated* \\
VC33 & 3 weeks, distilled water, orally +3 weeks HEC \\
& intratracheally \\
MnL33 & 3 weeks $14.48 \mathrm{mg} / \mathrm{b} . w$. kg $\mathrm{MnCL}_{2}$, orally +3 weeks \\
& MnO NPs $2.63 \mathrm{mg} / \mathrm{kg}$ b.w. intratracheally \\
MnH33 & 3 weeks $59.36 \mathrm{mg} / \mathrm{b} . w . \mathrm{kg} \mathrm{MnCL}_{2}$, orally +3 weeks \\
C6 & MnO NPs $2.63 \mathrm{mg} / \mathrm{kg}$ b.w. intratracheally \\
VC6 & 6 weeks, untreated* \\
MnL6 & 6 weeks, distilled water, orally \\
MnH6 & 6 weeks $14.84 \mathrm{mg} / \mathrm{kg}$ b.w. $\mathrm{MnCl}_{2}$, orally \\
\hline
\end{tabular}

${ }^{*} \mathrm{C} 33$ and $\mathrm{C} 6$ were two different groups of rats.

TABLE 2: Body weight gain of the rats during the treatment period.

\begin{tabular}{lcc}
\hline Group & Body weight gain $(\mathrm{g})$ & $\begin{array}{c}\text { Summed Mn dose } \\
(\mathrm{mg} \mathrm{Mn} \text { \%animal })\end{array}$ \\
\hline C3 & $161.7 \pm 14.4$ & - \\
VC3 & $149.9 \pm 11.2$ & - \\
MnL3 & $149.2 \pm 13.9(99.6 \%)$ & $17.94 \pm 0.52$ \\
MnH3 & $143.7 \pm 23.6(95.9 \%)$ & $71.58 \pm 2.93$ \\
C33 & $234.2 \pm 19.7$ & - \\
VC33 & $218.4 \pm 20.9$ & - \\
MnL33 & $210.9 \pm 17.2^{*}(96.5 \%)$ & $28.46 \pm 0.55$ \\
MnH33 & $195.2 \pm 27.6^{* * \#}(89.4 \%)$ & $83.42 \pm 2.95$ \\
C6 & $234.2 \pm 25.0$ & - \\
VC6 & $235.2 \pm 15.3$ & - \\
MnL6 & $226.1 \pm 17.3(96.2 \%)$ & $44.55 \pm 1.00$ \\
MnH6 & $211.0 \pm 19.3^{\#}(89.7 \%)$ & $178.43 \pm 8.53$ \\
\hline
\end{tabular}

For group codes, see Table 1. The data represent group averages (mean \pm $\mathrm{SD}, n=8$ ) of the difference between body weight on day 0 (before the first Mn administration) and the day of sacrifice.

*, ** $: P<0.05,0.01$ versus $C$; ${ }^{\#}: P<0.05$ versus VC.

Percent values in parentheses represent the weight gain in the Mn-treated groups compared to that in the corresponding VC group.

dissolved in PBS ( $\mathrm{pH}$ 7.4) to have a physiologically neutral vehicle in which unwanted surface interactions of the NPs were unlikely. The nanosuspension was instilled in the rats' trachea in brief diethyl ether anaesthesia (see [12] for details). The instilled volume was $1.0 \mathrm{~mL} / \mathrm{kg}$ b.w. The summed dose (see Table 2) was calculated by adding the $\mathrm{Mn}^{\circ}$ content of the daily administered volumes which were based on the daily body weights and the above-mentioned per kg doses. 
2.2. General Toxicological Investigation. Body weight of the animals was measured before every treatment, for followup and for calculating the exact doses to be administered that day. Growth curves were plotted and the weight gain over the whole treatment period was determined. Following electrophysiological recording (the last phase of the investigations) the rats used were sacrificed by an overdose of urethane (the anesthetic used in electrophysiology), were dissected, and organ weights were measured. Relative organ weights, as a routine index of toxicity, were calculated on the basis of brain weight. This was chosen so (using the rationale described in [15]) because the brain weight was not significantly different among the groups while body weight, the other usual calculation basis, showed some significant changes (see Table 2).

2.3. Electrophysiological Investigation. Electrophysiological recording was done on the day following the last $\mathrm{Mn}$ administration. Preparation for recording, and the recording itself, was performed in urethane anaesthesia $(1000 \mathrm{mg} / \mathrm{kg}$ i.p.) on 8 rats per group. The left hemisphere was surgically exposed (lidocaine spray was applied on the wounds) and spontaneous electrical activity (electrocorticogram, ECoG) was recorded from the primary somatosensory (SS), visual (VIS) and auditory (AUD) areas for 6 minutes using ball-tipped silver wire surface electrodes. From this, band spectrum according to the standard human EEG bands (delta to gamma [16]) was calculated. Then, evoked potentials (somatosensory, visual, and auditory) were recorded from the same sites by applying sensory stimuli in trains of 50 .

Somatosensory stimulation was done by square pulses (3-4 V; $0.05 \mathrm{~ms} ; 1,2$ and $10 \mathrm{~Hz}$ frequency) delivered through a pair of needles inserted into the contralateral whiskery skin. Visual stimulation was performed by flashes $(1 \mathrm{~Hz})$ of a highluminance white LED placed to the contralateral eye of the rat. For acoustic stimulation, clicks $(1 \mathrm{~Hz})$ were applied to the contralateral ear through the hollow ear bar of the stereotaxic frame. Onset latency and duration of the EPs was measured after averaging the 50 individual records. From the tail nerve, compound action potential was recorded by inserting a pair of needle electrodes at the base of the tail for stimulation, and another pair $50 \mathrm{~mm}$ distally for recording. Conduction velocity was calculated from this distance and the onset latency of the action potential. Relative refractory period was measured by double stimuli with $1-10 \mathrm{~ms}$ interstimulus interval, from the extra delay of the second potential. The complete electrophysiological work was performed by means of the software Neurosys 1.11 (Experimetria Ltd., Budapest, Hungary).

During the whole course of the experiment, the principles of the Ethical Committee for the Protection of Animals in Research of the University were strictly followed.

2.4. Statistical Evaluation. The distribution of data was checked for normality by means of the Kolmogorov-Smirnov test. Data analysis was done by one-way ANOVA. Post hoc analysis of group differences was performed by LSD test, setting the probability level at $P>0.05$.

\section{Results}

3.1. Body and Organ Weights. Oral Mn exposure caused only a light, nonsignificant reduction in the treated rats' body weight gain after 3 weeks, and after 6 weeks with the lower dose. Only after 6 weeks and the higher dose (MnH6) did weight gain show significant reduction. Where, however, intratracheal exposure followed the oral one (MnL33, $\mathrm{MnH33)}$ the reduction of weight gain was always significant. Compared to the corresponding controls, reduction of weight gain was somewhat stronger in the group $\mathrm{MnH} 33$ than in MnH6, although the calculated summed Mn dose was much lower in MnH33 than in MnH6 (Table 2). This suggested a potentially more efficient absorption of $\mathrm{Mn}$ from the airways than from the gastrointestinal tract. It is also noteworthy that in VC33 the weight gain reduction versus the corresponding untreated control was moderate (although present), indicating that the procedure of intratracheal administration itself (including repeated etherization) had no significant general toxic effect. The graph in Figure 1(a) shows the time course of weight gain (with an abrupt change at the beginning of intratracheal application of Mn NPs, but not of vehicle alone) while Figure 1(b) demonstrates that the individual rats' daily weight gain was more affected in the oral + intratracheal treatment groups in spite of the lower summed dose.

Among the relative organ weights, that of the lung, liver and adrenals showed significant changes (Table 3; the table also lists the absolute data of brain weight to show the basis of calculation). Lung weight was strongly affected by the intratracheal Mn treatment (MnL33, MnH33) and less strongly also by the intratracheal vehicle administration (VC33). The lungs excised from rats with intratracheal Mn exposure had typically an emphysematic appearance with visible dark spots of Mn deposition.

3.2. Electrophysiological Effects. There were no prominent changes in the spontaneous cortical activity. A trend of decreased power in the low-frequency (delta, and to a lesser extent, theta) bands, and increase in the fast beta 2 and gamma bands was observed in all three cortical areas but without significance.

On the sensory EPs, Mn treatment generally caused a latency increase. As seen in Figure 2, SS EP latency was universally increased in the treated rats versus vehicle control. At the same time, the latency was also influenced by the frequency of stimulation, and this frequency-dependent lengthening was in the treated groups also typically more intense. Figure 2 also shows that latency increase in MnL33 was about equal to that in MnL6 at all stimulation frequencies, and also in $\mathrm{MnH} 33$ to $\mathrm{MnH} 6$ at 1 and $2 \mathrm{~Hz}$ stimulation; a relationship similar to that seen with the body weight gain (see Figure 1(b) and Table 2).

The latency of VIS and AUD EPs was also lengthened by Mn exposure (Figure 3) but the relationship of the groups with 3 weeks oral +3 weeks intratracheal versus 6 weeks oral treatment was not like in case of the SS EP. In case of all three sensory modalities, however, within one treatment variation the higher dose caused more lengthening of the latency: 


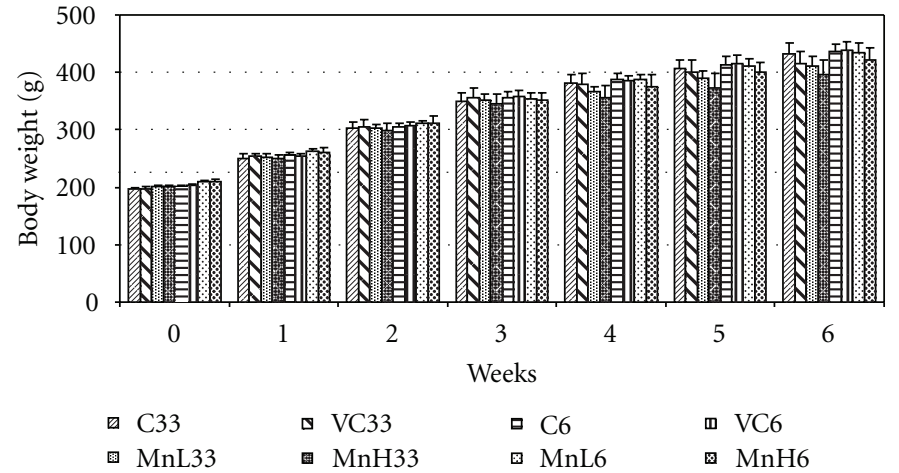

(a)

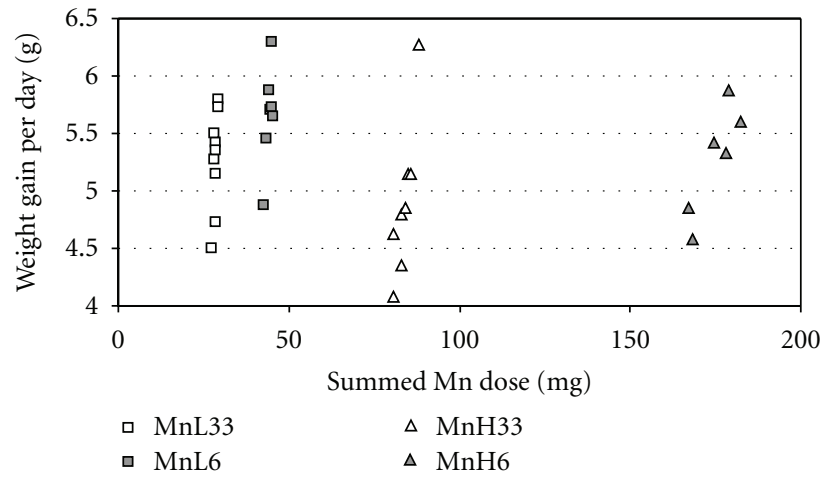

(b)

Figure 1: (a) Time course of the control and treated rats' weight gain in the 3 weeks oral +3 weeks intratracheal and the 6 weeks oral treatment. Mean \pm SD, $n=8$. Significance marking omitted for clarity; for this, see Table 2. (b) Relationship of summed Mn dose (abscissa) and daily weight gain (ordinate) of individual rats belonging to the treatment groups given in the insert. Daily weight gain was calculated by dividing total weight gain with the length of treatment.

TABLE 3: Relative organ weights of the lungs, liver, and adrenals, and the absolute brain weights used as calculation basis.

\begin{tabular}{lcccc}
\hline Groups & Brain absolute weight $(\mathrm{g})$ & \multicolumn{3}{c}{ Relative organ weights } \\
& & Lungs & Liver & $0,0070 \pm 0.0010$ \\
C3 & $1.989 \pm 0.061$ & $0,170 \pm 0.009$ & $1,856 \pm 0.104$ & $1,606 \pm 0.103^{*}$ \\
VC3 & $1,999 \pm 0.072$ & $0,200 \pm 0.021^{*}$ & $1,837 \pm 0.207^{\#}$ & $0,0085 \pm 0.0027$ \\
MnL3 & $2,038 \pm 0.095$ & $0,167 \pm 0.017^{\#}$ & $1,840 \pm 0.299$ & $0,0081 \pm 0.0011^{\mathrm{X}}$ \\
MnH3 & $1,974 \pm 0.111$ & $0,224 \pm 0.055^{* \mathrm{X}}$ & $1,534 \pm 0.101$ & $0,0061 \pm 0.0013$ \\
C33 & $2,076 \pm 0.061$ & $0,169 \pm 0.020$ & $1,563 \pm 0.113$ & $0,0062 \pm 0.0007$ \\
VC33 & $2,092 \pm 0.067$ & $0,214 \pm 0.009^{* *}$ & $1,626 \pm 0.133$ & $0,0078 \pm 0.0014^{* \#}$ \\
MnL33 & $2,053 \pm 0.043$ & $0,391 \pm 0.056^{* * * \# \# \#}$ & $1,450 \pm 0.075^{\# \mathrm{X}}$ & $0,0073 \pm 0.0014^{*}$ \\
MnH33 & $2,106 \pm 0.077$ & $0,372 \pm 0.018^{* * * \# \# \#}$ & $1,512 \pm 0.102$ & $0,0057 \pm 0.0006$ \\
C6 & $2,127 \pm 0.047$ & $0,151 \pm 0.013$ & $1,443 \pm 0.088$ & $0,0064 \pm 0.0014$ \\
VC6 & $2,092 \pm 0.028$ & $0,154 \pm 0.013$ & $1,546 \pm 0.081$ & $0,0070 \pm 0.0009^{*}$ \\
MnL6 & $2,124 \pm 0.076$ & $0,149 \pm 0.011$ & $1,430 \pm 0.106$ & $0,0063 \pm 0.0008$ \\
MnH6 & $2,103 \pm 0.060$ & $0,165 \pm 0.022$ & & \\
\hline
\end{tabular}

For group codes, see Table 1 ; for the calculation, see Section 2 . The data are mean $\pm \mathrm{SD}(n=8)$.

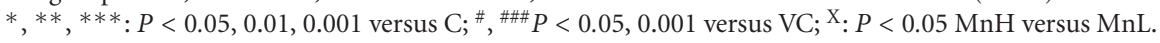

an indication of dose dependence, an exception being MnH33 versus MnL33 in case of SS EP. The duration of EPs showed no consistent alteration.

The conduction velocity of the tail nerve was reduced in the treated rats. As seen in Figure 4(a), this effect was also dose dependent, and the effect in the group MnL33 was stronger than that seen in MnL6. The relative refractory period of the tail nerve (Figure 4(b)) was also significantly altered by Mn application.

\section{Discussion}

The most conspicuous result of the above experiments was the disproportionately strong effect seen with oral + intratracheal combined Mn exposure. That is, the change in body weight gain and in several electrophysiological parameters was more, or at least not less, expressed in the groups MnL33 and MnH33 (oral + intratracheal) than in MnL6 and MnH6 (oral only), although in the latter the applied summed dose was much higher (Table 2). This pointed to possible differences in the absorption and/or to qualitative differences in the toxicity of the two forms of $\mathrm{Mn}$.

From the intestinal system, $\mathrm{Mn}$ is absorbed to only 10 $15 \%[5,17]$. This is the physiological way of covering $\mathrm{Mn}$ demand so it is a regulated process where Mn overload leads to decreased absorption rate. From the airways, however, the absorption of NPs can be much more efficient. NPs translocate readily to extrapulmonary sites by a mechanism involving transcytosis (caveola formation) across epithelia of the respiratory tract into the interstitium, with subsequent access to the blood and distribution throughout the body [1]. Mn containing NPs can reach the brain from the blood through the capillary endothelial cells in the blood-brain barrier, and through the choroid plexuses [18]. Inhaled Mn absorbed this way is likely to reach its target sites before 


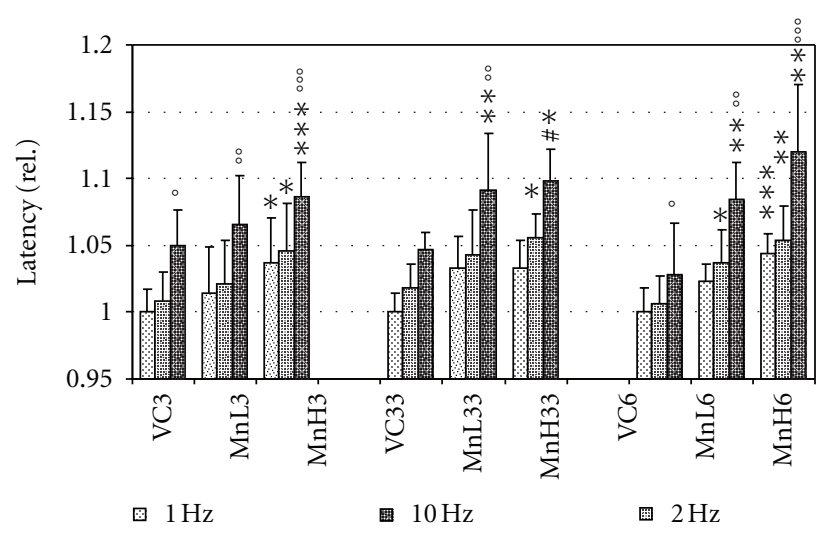

FIGURE 2: Latency of the somatosensory evoked potential in the control and treated rats, recorded with 1,2 , and $10 \mathrm{~Hz}$ stimulation frequency (see insert). Mean $+\mathrm{SD}, n=8$. The data displayed are relative, calculated to the value obtained from the vehicle-treated rats at $1 \mathrm{~Hz}$ frequency as basis of comparison. ${ }^{*},{ }^{* *},{ }^{* * *}: P<0.05$, $0.01,0.001$ treated versus VC; \#, \#\# $P<0.05,0.01$ MnL33 versus MnL6; ${ }^{\circ},{ }^{\circ},{ }^{\circ}: 2 \mathrm{~Hz}$ or $10 \mathrm{~Hz}$ stimulation versus $1 \mathrm{~Hz}$, within one treatment group.

biliary excretion, the main mechanism of eliminating excess $\mathrm{Mn}$ from the organism [19]. In a more direct way, Mncontaining NPs enter the sensory nerve endings embedded in the epithelia of the airways (primarily, but not exclusively, in the olfactory mucosa) and migrate transsynaptically up to the brain [20].

Even if there was no tissue Mn level measurement in the present work, organ Mn load data of previous experiments with the same doses and routes of application [12-14] favor the reasoning that, on the basis of the observed toxic effects, inhaled NPs cause internal exposure more efficiently than ingested, dissolved Mn. An alternative, equally feasible explanation is that NPs had higher potency in inducing oxidative stress than dissolved $\mathrm{Mn}$, keeping in mind that the surface chemistry of various oxide NPs is favorable for inducing oxidative stress [1].

Oxidative stress, first of all, contributed probably to the lung effects. Welding fumes containing $\mathrm{Mn}$ were reported to cause oxidative stress and inflammation [21]. In the liver, weight decrease was seen in rats with oral + intratracheal (MnL33, MnH33) exposure, but not in those receiving oral exposure only. A similar effect of NPs on the liver was seen also previously (with Mn NPs: Oszlánczi et al. [13]; but also with Cd NPs: Horváth et al. [22]). The dependence of the effect more on the nanoparticulate character than on the chemical composition is supported by literature data on in vivo liver damage related to oxidative stress in rats treated with intratracheal $\mathrm{TiO}_{2} \mathrm{NPs}$ [23], and oxidative damage of in vitro human hepatic cells on exposure to $\mathrm{ZnO}$ NPs [24]. The decreased body weight gain in rats exposed to Mn NPs (oral + intratracheal treatment: groups MnL33 and MnH33) is also an indication of stress (as suggested in [25]) especially in combination with the increased weight of the adrenals in these groups (see Tables 2 and 3). Mn-induced systemic oxidative stress has been reported to act also in the brain

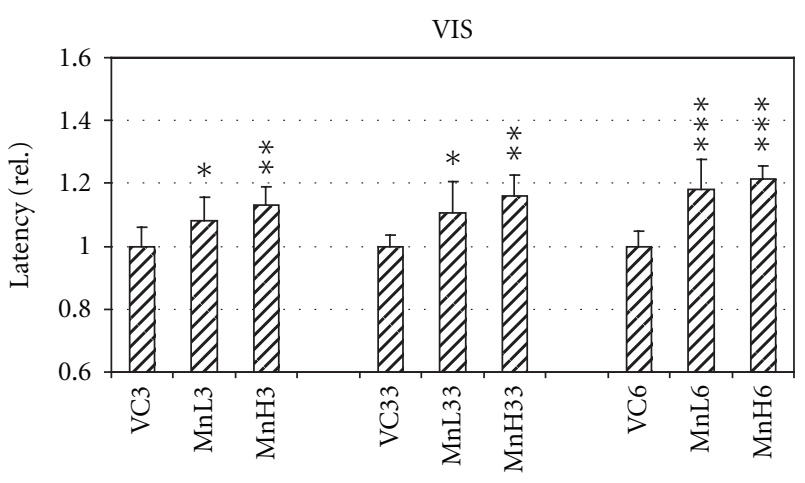

(a)

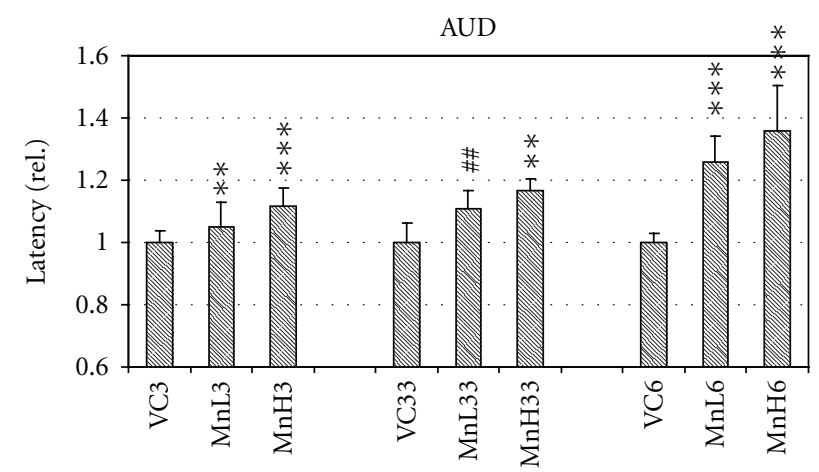

(b)

FIGURE 3: Latency of the visual (a) and auditory (b) evoked potentials in the control and treated rats. Mean $+\mathrm{SD}, n=8$. The relative data were calculated as given at Figure $2 .{ }^{*},{ }^{*},{ }^{* * *}$ : $P<0.05,0.01,0.001$ treated versus VC; \#\# $P<0.01$ MnL33 versus MnL6.

and contribute to functional alterations [26]. Astrocytes were found to suffer oxidative damage on in vitro Mn exposure [27]. Others, however, found no connection between $\mathrm{Mn}$ neurotoxicity and ROS generation [28].

At the level of neurons, energetic shortage caused by Mn-dependent inhibition of mitochondrial complex II [29] and complex III [30] may lead to hypofunction of ion pumps and/or disturbed turnover of transmitters, and so to weakened propagation of the excitation. Increased frequency-dependent lengthening of the SS EP latency in treated versus control rats (see Figure 2) may be due to that. The mentioned mechanism of action was probably present not only on the cortical and subcortical level but along the whole sensory pathway because the pulse conduction velocity of the tail nerve (primarily of its fast myelinated axons, largely contributing to the recorded compound action potential and being especially sensitive to ATP depletion [31]) — and, even more importantly, the relative refractory period, an indicator of the interaction of successive excitation processes-was also affected. Removal of glutamate from the synaptic cleft is slowed by the direct effect of elevated extracellular Mn level [32] and indirectly by the blocking effect of Mn-induced ROS on the high-affinity glutamate transporters [33]. Accumulation of excess glutamate at all transmission sites of the ascending sensory pathways may 


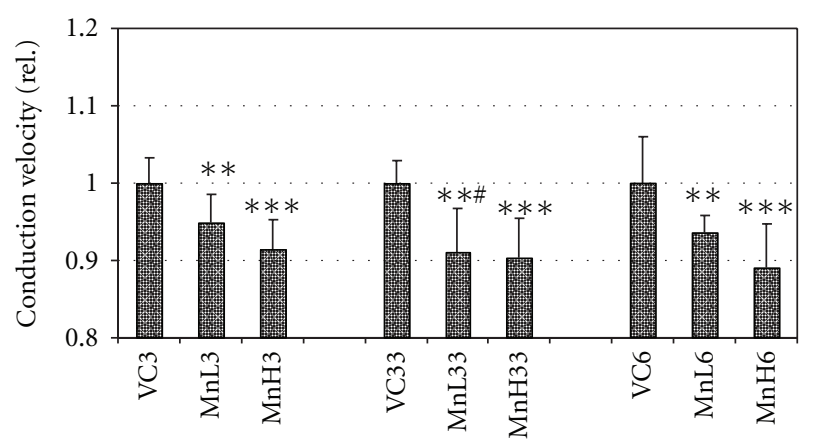

(a)

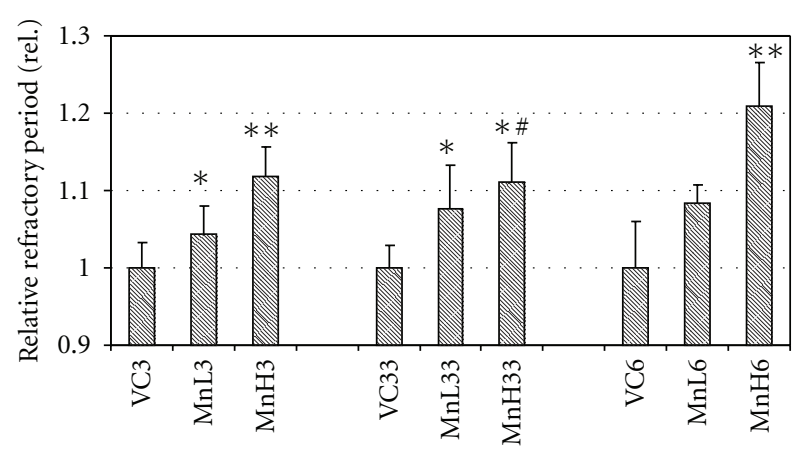

(b)

FIgURE 4: Changes of the nerve conduction velocity (a) and relative refractory period (b) in the tail nerve of the rats. Mean $+\mathrm{SD}, n=8$. The relative data were calculated as given at Figure 2 . $^{*}, * *, * * *$ : $P<0.05,0.01,0.001$ treated versus VC; ${ }^{*}: P<0.05,0.01 \mathrm{MnL} 33$ versus MnL6.

have resulted, after several weeks of $\mathrm{Mn}$ exposure, in receptor desensitization, another factor leading to increased EP latency [34]. The excitotoxic effect of excess glutamate cannot be ruled out either.

The results confirm the general and neurological toxicity of both forms of $\mathrm{Mn}$ applied, and emphasize the higher toxic potential of Mn-containing NPs as opposed to the dissolved form. Both of these forms, however, can cause human exposure, separately and simultaneously, and our present results potentially suggest that preceding (or concurrent) oral Mn burden may increase the sensitivity to inhaled Mn. This problem deserves further investigation, for example, in model systems similar to ours-partly because exposure from several sources or by several ways is a reallife possibility, and partly because $\mathrm{Mn}$ level in human biological samples is apparently not a reliable indicator of CNS damage [35] and, not less importantly, is not sensitive to the physicochemical form of the absorbed Mn. So, eventual development of neurofunctional biomarkers, based for example on the electrophysiological effects examined in this work, may be of importance-primarily in contributing to sensitivity while Mn specificity will have to be provided by other, probably chemical, markers.

\section{References}

[1] G. Oberdörster, E. Oberdörster, and J. Oberdörster, "Nanotoxicology: an emerging discipline evolving from studies of ultrafine particles," Environmental Health Perspectives, vol. 113, no. 7, pp. 823-839, 2005.

[2] J. P. Ryman-Rasmussen, J. E. Riviere, and N. A. MonteiroRiviere, "Surface coatings determine cytotoxicity and irritation potential of quantum dot nanoparticles in epidermal keratinocytes," Journal of Investigative Dermatology, vol. 127, no. 1, pp. 143-153, 2007.

[3] R. M. Bowler, H. A. Roels, S. Nakagawa et al., "Dose-effect relationships between manganese exposure and neurological, neuropsychological and pulmonary function in confined space bridge welders," Occupational and Environmental Medicine, vol. 64, no. 3, pp. 167-177, 2007.

[4] E. H. Hernandez, G. Discalzi, P. Dassi, L. Jarre, and E. Pira, "Manganese intoxication: the cause of an inexplicable epileptic syndrome in a 3 year old child," NeuroToxicology, vol. 24, no. 4-5, pp. 633-639, 2003.

[5] C. D. Davis, T. L. Wolf, and J. L. Greger, "Varying levels of manganese and iron affect absorption and gut endogenous losses of manganese by rats," Journal of Nutrition, vol. 122, no. 6, pp. 1300-1308, 1992.

[6] T. Ohtake, K. Negishi, K. Okamoto et al., "Manganese-induced parkinsonism in a patient undergoing maintenance hemodialysis," American Journal of Kidney Diseases, vol. 46, no. 4, pp. 749-753, 2005.

[7] X. G. Kondakis, N. Makris, M. Leotsinidis, M. Prinou, and T. Papapetropoulos, "Possible health effects of high manganese concentration in drinking water," Archives of Environmental Health, vol. 44, no. 3, pp. 175-178, 1989.

[8] R. Kawamura, H. Ikuta, S. Fukuzumi, R. Yamada, and S. Tsubaki, "Intoxication by manganese in well water," Kitasato Archives of Experimental Medicine, vol. 18, pp. 145-171, 1941.

[9] A. Woolf, R. Wright, C. Amarasiriwardena, and D. Bellinger, "A child with chronic manganese exposure from drinking water," Environmental Health Perspectives, vol. 110, no. 6, pp. 613-616, 2002.

[10] H. Komaki, S. I. Maisawa, K. Sugai, Y. I. Kobayashi, and T. Hashimoto, "Tremor and seizures associated with chronic manganese intoxication," Brain and Development, vol. 21, no. 2, pp. 122-124, 1999.

[11] T. Halatek, H. Sinczuk-Walczak, M. Szymcsak, and K. Rydzynski, "Neurological and respiratory symptoms in shipyard welders exposed to manganase," International Journal of Occupational and Environmental Health, vol. 18, pp. 265-274, 2005.

[12] L. Sárközi, E. Horváth, Z. Kónya et al., "Subacute intratracheal exposure of rats to manganese nanoparticles: behavioral, electrophysiological, and general toxicological effects," Inhalation Toxicology, vol. 21, no. 1, pp. 83-91, 2009.

[13] G. Oszlánczi, T. Vezér, L. Sárközi, E. Horváth, Z. Kónya, and A. Papp, "Functional neurotoxicity of Mn-containing nanoparticles in rats," Ecotoxicology and Environmental Safety, vol. 73, no. 8, pp. 2004-2009, 2010.

[14] T. Vezér, A. Papp, Z. Hoyk, C. Varga, M. Náray, and L. Nagymajtényi, "Behavioral and neurotoxicological effects of subchronic manganese exposure in rats," Environmental Toxicology and Pharmacology, vol. 19, no. 3, pp. 797-810, 2005.

[15] K. Schärer, "The effect of chronic underfeeding on organ weights of rats," Toxicology, vol. 7, no. 1, pp. 45-56, 1977.

[16] E. R. Kandel and J. H. Schwartz, Principles of Neural Science, Elsevier, New York, NY, USA, 1985. 
[17] G. J. Li, B. S. Choi, X. Wang, J. Liu, M. P. Waalkes, and W. Zheng, "Molecular mechanism of distorted iron regulation in the blood-CSF barrier and regional blood-brain barrier following in vivo subchronic manganese exposure," NeuroToxicology, vol. 27, no. 5, pp. 737-744, 2006.

[18] J. S. Crossgrove and R. A. Yokel, "Manganese distribution across the blood-brain barrier: IV. Evidence for brain influx through store-operated calcium channels," NeuroToxicology, vol. 26, no. 3, pp. 297-307, 2005.

[19] M. E. Andersen, J. M. Gearhart, and H. J. Clewell, "Pharmacokinetic data needs to support risk assessments for inhaled and ingested manganese," NeuroToxicology, vol. 20, no. 2-3, pp. 161-171, 1999.

[20] H. Tjälve and J. Henriksson, "Uptake of metals in the brain via olfactory pathways," NeuroToxicology, vol. 20, pp. 329-337, 1999.

[21] J. D. McNeilly, M. R. Heal, I. J. Beverland et al., "Soluble transition metals cause the pro-inflammatory effects of welding fumes in vitro," Toxicology and Applied Pharmacology, vol. 196, no. 1, pp. 95-107, 2004.

[22] E. Horváth, G. Oszlánczi, Z. Máté et al., "Nervous system effects of dissolved and nanoparticulate cadmium in rats in subacute exposure," Journal of Applied Toxicology, vol. 31, no. 5, pp. 471-476, 2011.

[23] G. Liang, Y. Pu, L. Yin et al., "Influence of different sizes of titanium dioxide nanoparticles on hepatic and renal functions in rats with correlation to oxidative stress," Journal of Toxicology and Environmental Health, Part A, vol. 72, no. 11, pp. 740-745, 2009.

[24] V. Sharma, D. Anderson, and A. Dhawan, "Zinc oxide nanoparticles induce oxidative stress and genotoxicity in human liver cells (HepG2)," Journal of Biomedical Nanotechnology, vol. 7, no. 1, pp. 98-99, 2011.

[25] G. T. Rezin, M. R. Cardoso, C. L. Gonçalves et al., "Inhibition of mitochondrial respiratory chain in brain of rats subjected to an experimental model of depression," Neurochemistry International, vol. 53, no. 6-8, pp. 395-400, 2008.

[26] D. S. Ávila, P. Gubert, R. Fachinetto et al., "Involvement of striatal lipid peroxidation and inhibition of calcium influx into brain slices in neurobehavioral alterations in a rat model of short-term oral exposure to manganese," NeuroToxicology, vol. 29, no. 6, pp. 1062-1068, 2008.

[27] C. J. Chen and S. L. Liao, "Oxidative stress involves in astrocytic alterations induced by manganese," Experimental Neurology, vol. 175, no. 1, pp. 216-225, 2002.

[28] M. D. Taylor, K. M. Erikson, A. W. Dobson, V. A. Fitsanakis, D. C. Dorman, and M. Aschner, "Effects of inhaled manganese on biomarkers of oxidative stress in the rat brain," NeuroToxicology, vol. 27, no. 5, pp. 788-797, 2006.

[29] E. A. Malecki, "Manganese toxicity is associated with mitochondrial dysfunction and DNA fragmentation in rat primary striatal neurons," Brain Research Bulletin, vol. 55, no. 2, pp. 225-228, 2001.

[30] J. Zhang, V. A. Fitsanakis, G. Gu et al., "Manganese ethylenebis-dithiocarbamate and selective dopaminergic neurodegeneration in rat: a link through mitochondrial dysfunction," Journal of Neurochemistry, vol. 84, no. 2, pp. 336-346, 2003.

[31] V. A. Fitsanakis and M. Aschner, "The importance of glutamate, glycine, and $\gamma$-aminobutyric acid transport and regulation in manganese, mercury and lead neurotoxicity," Toxicology and Applied Pharmacology, vol. 204, no. 3, pp. 343-354, 2005.
[32] A. S. Hazell and M. D. Norenberg, "Manganese decreases glutamate uptake in cultured astrocytes," Neurochemical Research, vol. 22, no. 12, pp. 1443-1447, 1997.

[33] D. Trotti, N. C. Danbolt, and A. Volterra, "Glutamate transporters are oxidant-vulnerable: a molecular link between oxidative and excitotoxic neurodegeneration?" Trends in Pharmacological Sciences, vol. 19, no. 8, pp. 328-334, 1998.

[34] D. Centonze, P. Gubellini, G. Bernardi, and P. Calabresi, "Impaired excitatory transmission in the striatum of rats chronically intoxicated with manganese," Experimental Neurology, vol. 172, no. 2, pp. 469-476, 2001.

[35] D. Smith, R. Gwiazda, R. Bowler et al., "Biomarkers of Mn exposure in humans," American Journal of Industrial Medicine, vol. 50, no. 11, pp. 801-811, 2007. 

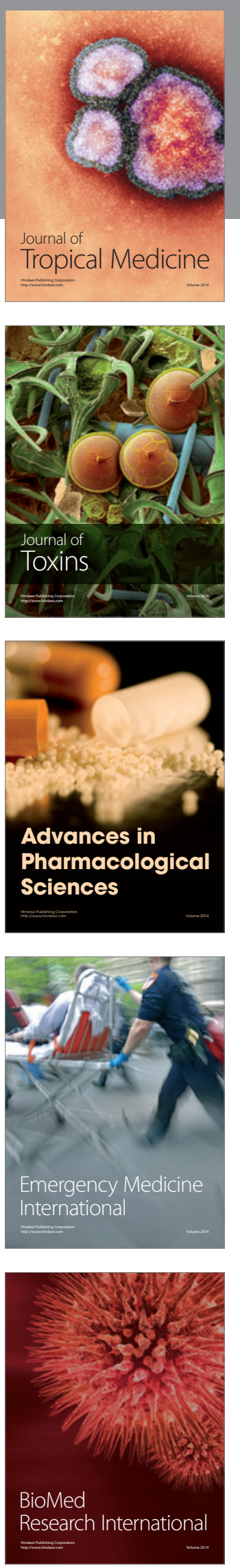
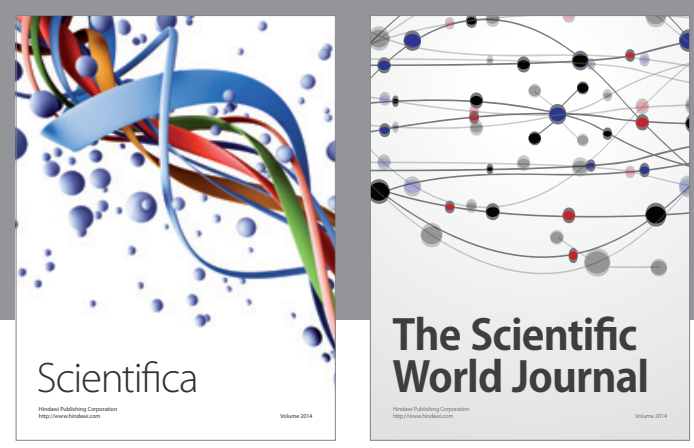

The Scientific World Journal
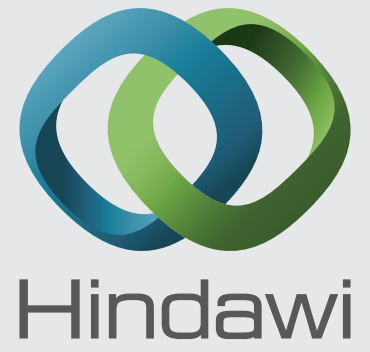

Submit your manuscripts at

http://www.hindawi.com
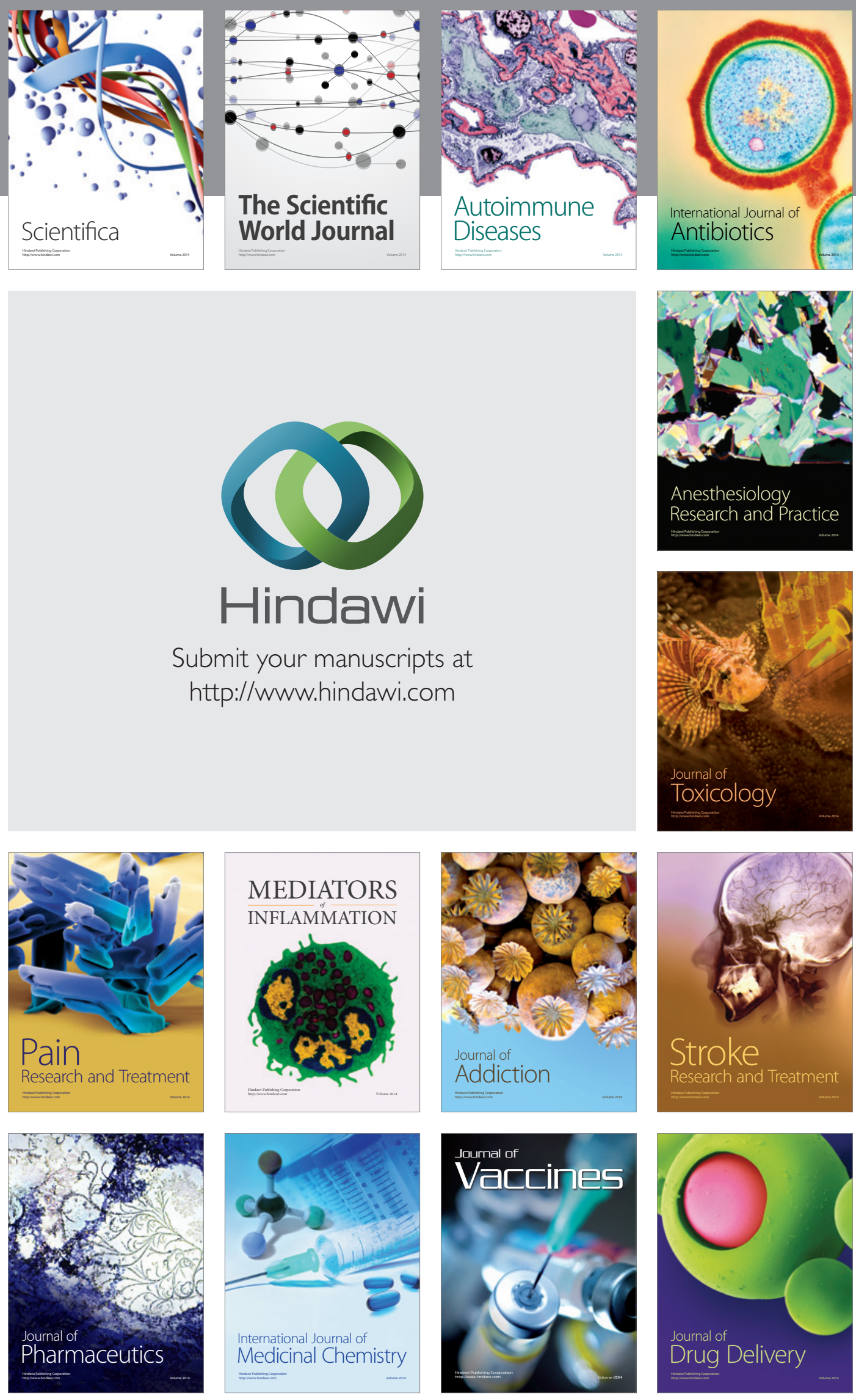